\title{
Left Renal Cell Carcinoma with a Tumor Thrombus in the Inferior Vena Cava: A Case Report
}

\author{
Changqin Jiang and Chaozhao Liang*
}

Department of Urology, The First Affiliated Hospital of Anhui Medical University, China

*Corresponding author: Chaozhao Liang , The Department of Urology , The First Affiliated Hospital of Anhui Medical University, 218, jixi, Ave, He Fei, Anhui-230022, China, E-mail: jcq.2008@163.com

\begin{abstract}
A case of Left renal cell carcinoma with a tumor thrombus in the inferior vena cava in a 79-years-old woman is presented. Renal Cell Carcinoma (RCCs) is the most common malignancy of the kidney. Because of shorter right renal vein, the right renal cell carcinoma is more common, the cases of left renal cell carcinoma merging inferior vena cava cancer embolus were rare compared to those in the right. Here, we reported a case is with left renal cell carcinoma with a tumor thrombus in the inferior vena cava.
\end{abstract}

\section{Keywords}

Renal cell carcinoma, Thrombus, Kidney, Inferior vena cava, Surgery

\section{Introduction}

Renal Cell Carcinoma (RCCs) is the most common malignancy arising from the kidney. While local renal tumor growth and extension may involve the perirenal fat, adrenal glands, renal vein, inferior vena cava, urinary collecting system and/or adjacent retroperitoneal structure, left renal cell carcinoma with a tumor thrombus in the inferior vena cava is extremely rare. To our best knowledge, only few cases of left renal cell carcinoma with inferior vena caval thrombus have been reported. Here we reported a fortuitous case suffering from left renal cell carcinoma with a tumor thrombus in the inferior vena cava.

\section{Case presentation}

A 79-years-old woman, with no past notable medical history, present with left renal mass found in an examination more than 10 days ago. She felt weight down, in order to seek further treatment; she was admitted to our department. Chiefly complained that she lost about $15 \mathrm{~kg}$ in weight, accompanied by fatigue, anorexia, no chills, and fever. No positive finding was found during the urological physical examination Auxiliary examination: CT and MRI showed left kidney cancer merge left renal vein and inferior vena cava cancer embolus. A pre-operative preparation was performed. This operation was performed by liver physician and kidney physicians. A $25 \mathrm{~cm}$ abdominal herringbone incision was used to enter the abdominal cavity layer by layer, the abdominal exploration showed a small amount of ascites, mild liver cirrhosis. After cutting the ligaments of liver, the liver and vena cava were fully mobilized, and then the superior hepatic vena cava, first portal and left renal vein and vena cava below renal vein were separated to be placed with blockers. The tumor was located at the lower pole of the left kidney with a diameter of about $8.0 \mathrm{~cm}$, the cancer embolus was palpable in renal vein and vena cava, the vena cava cancer embolus reached hepatic diaphragm. The venous flow was blocked by blockers, and then vena cava was transected to quickly extract the vena cava cancer embolus. After cutting off the left renal vein, the vena cava incision was stapled by 0 vascular sutures with double continuous anastomosis technique. Then the revascularization of venous flow was performed, the blocking time was about $10 \mathrm{~min}$, next the left side of the peritoneum was cut, and the left kidney and tumor were mobilized outside the Gerota's fascia following by transection of left renal artery and ureter until the left kidney, cancer, renal vein cancer embolus and perirenal fat were completely removed. The procedure was performed successfully. The dissection for specimen showed a tumor diameter of $8.0 \mathrm{~cm}$, a renal vein embolus size of $6.0 \mathrm{~cm}$, a vena cava embolus size of $8.0 \mathrm{~cm}$. The postoperative nutritional support and treatment was conducted, the patient recovered well. Pathological examination showed: left renal clear cell carcinoma (Fuhrman's nuclear grading: II).The patients did not receive a post operative chemotherapy. No recurrence and metastasis was found after a two-year follow-up (Figure 1-3).

\section{Discussion}

A lot of clinical literatures reported the renal cell carcinoma merge inferior vena cava cancer embolus. Because of shorter right renal vein, the right kidney cancer is more common, the cases of left kidney cancer merging inferior vena cava cancer embolus were rare compared to those in right. Many literatures reported that the incidence of renal carcinoma merging inferior vena cava cancer embolus was within 9-14\%, in which, $14-39 \%$ of cancer embolus can invade into the right atrium $[1,2]$. According to cancer embolus classification, the type I infrahepatic, type II intrahepatic, type III suprahepatic, type IV embolus can invade into atrium [3], the patient with renal cell carcinoma merging inferior vena cava cancer embolus in this paper belonged to type III. The clinical manifestation of the renal cell carcinoma merging inferior vena cava cancer embolus is similar to renal carcinoma, so the former's diagnosis mainly depends on B ultrasound and CT or MRI. CT 3d reconstruction for venous cancer embolus also can reach the similar sensitivity and specificity of MRI diagnosis [4]. The current preferred method for the treatment of renal cell carcinoma merging inferior vena cava cancer embolus is surgery, even in the presence of distant metastasis, the radical surgery is still considered as the only chance for long-term survival [5]. Researchers believed that the infiltration degree of vena cava cancer embolus does not change the prognosis of kidney cancer

\section{Clinmed International Library}

Citation: Jiang C, Liang C (2015) Left Renal Cell Carcinoma with a Tumor Thrombus in the Inferior Vena Cava: A Case Report. Int J Surg Res Pract 2:024

Received: June 10, 2015: Accepted: July 26, 2015: Published: July 30, 2015 Copyright: (c) 2015 Jiang C. This is an open-access article distributed under the terms of the Creative Commons Attribution License, which permits unrestricted use, distribution, and reproduction in any medium, provided the original author and source are credited. 


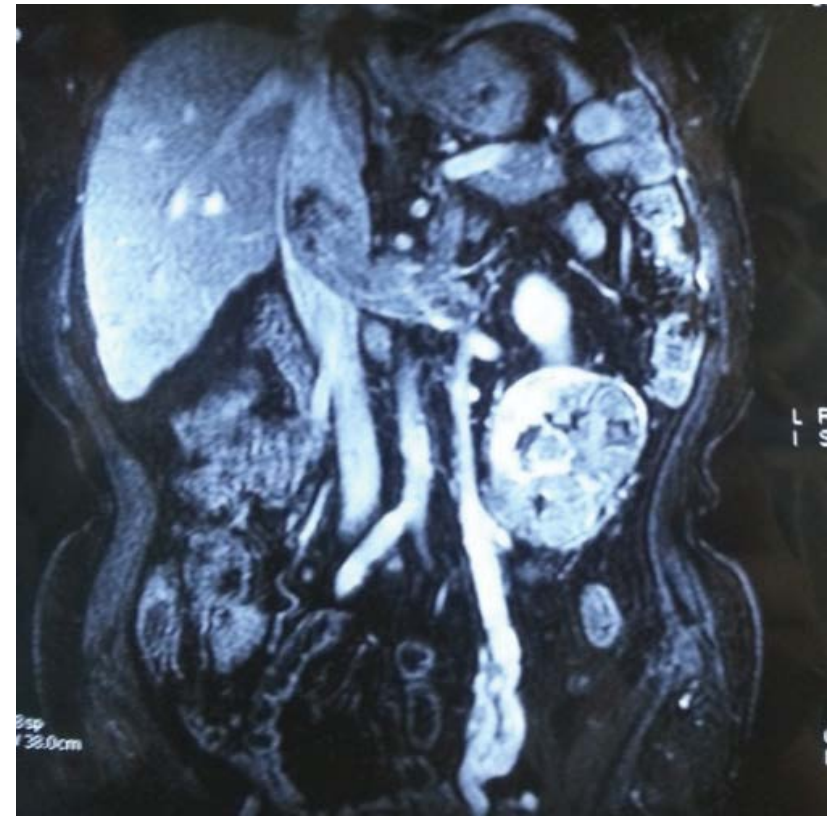

Figure 1: 3d CT showed left kidney cancer merge renal vein and the inferior vena cava with tumor thrombus

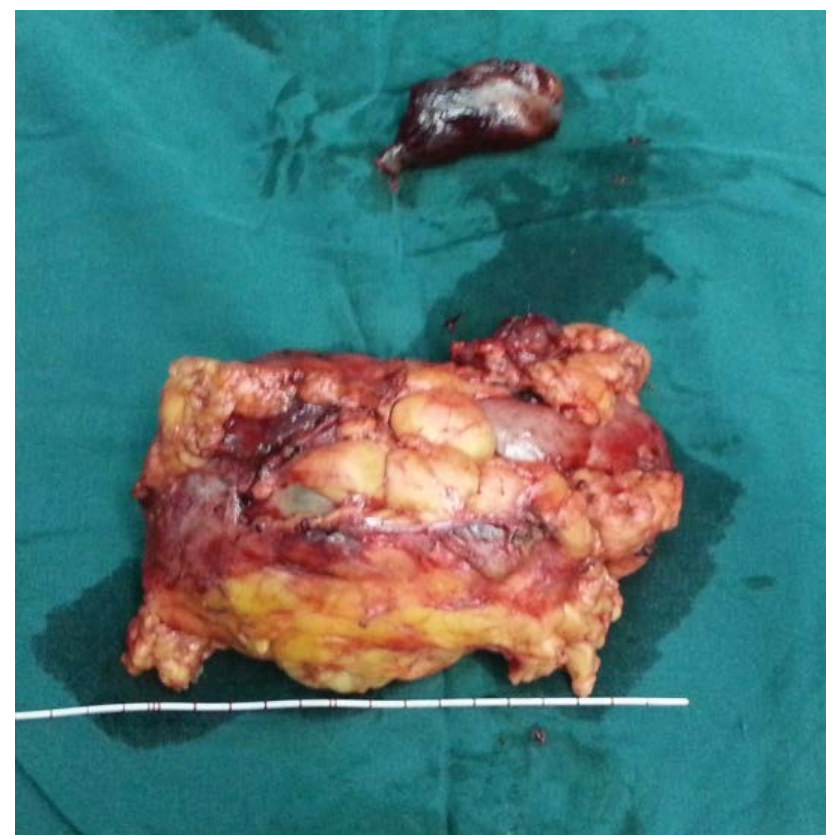

Figure 2: Postoperative specimen showed left kidney cancer and cancer thrombus

patients; for the presence of the vena cava wall invasion, the complete resection of the infiltrated inferior vena cava wall will leave a survival rate with no significant difference compared with that in patients without vena cava invasion [6]. The cancer embolus, therefore, is considered not an independent poor prognostic factor for patients with kidney cancer; for advanced patients, the cytoreductive surgery is also beneficial for the further treatment and rehabilitation. The selection of surgical methods depends largely on the type of the vena cava cancer embolus and the absence or presence of vena cava wall infringement. For the type I, II and III cavity vein cancer embolus, the patients without infiltrated caval vein can undergo procedures without cardiopulmonary bypass; for the type IV vena cava cancer embolus and infiltrated caval vein, the patients are required to undergo procedures with cardiopulmonary bypass. And, many surgeries also required more than one surgeon from different departments. In procedure, the full exposure of operative field is necessary to prevent hemorrhage and embolus shedding to cause pulmonary embolism.

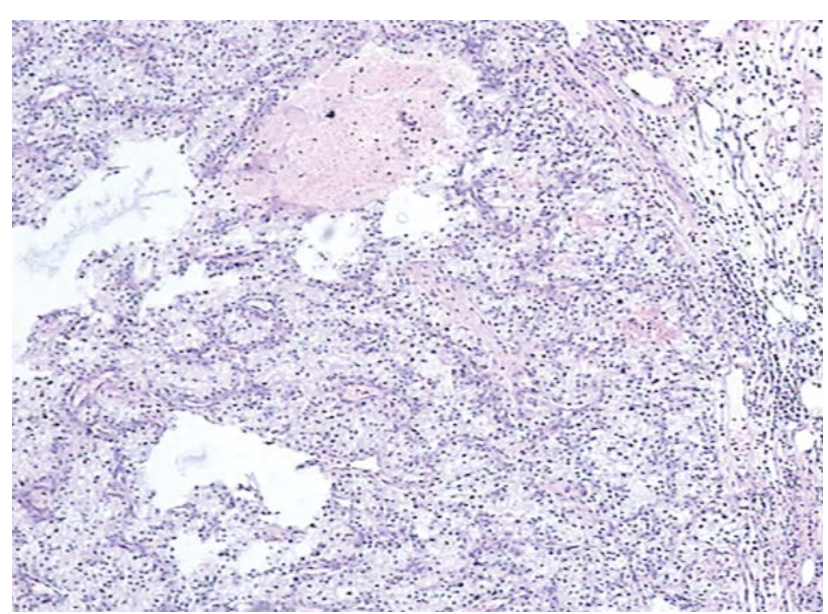

Figure 3: Pathological examination showed: left renal clear cell carcinoma, Fuhrman's nuclear grading: II, (HEx400).

\section{Acknowledgment}

I would like to thank all staffs for their support and assistance. This study is supported by Clinical Key Subjects Program of the Ministry of Public Health (Urology), National Natural Science Foundation of China $(81170698,81370856)$, the cultivation project for NSFC at Anhui Medical University (No. 2013KJ13).

Reprint Address: Changqin Jiang, MM, Department of Urology, The First Affiliated Hospital of Anhui Medical University and Institute of Urology $218 \mathrm{Jix}$ Road Shushan District, Hefei 230022 China.

\section{Author Disclosure Statement}

No competing financial interests exist.

\section{References}

1. Parekh DJ, Cookson MS, Chapman W, Harrell F Jr, Wells N, et al. (2005) Renal cell carcinoma with renal vein and inferior vena caval involvement: clinicopathological features, surgical techniques and outcomes. J Urol 173: 1897-1902.

2. Terakawa T, Miyake H, Takenaka A, Hara I, Fujisawa M (2007) Clinical outcome of surgical management for patients with renal cell carcinoma involving the inferior vena cava. Int J Urol 14: 781-784.

3. Terakawa T, Miyake H, Takenaka A, Hara I, Fujisawa M (2007) Clinical outcome of surgical management for patients with renal cell carcinoma involving the inferior vena cava. Int J Urol 14: 781-784.

4. Hallscheidt PJ, Fink C, Haferkamp A, Bock M, Luburic A, et al. (2005) Preoperative staging of renal cell carcinoma with inferior vena cava thrombus using multidetector $\mathrm{CT}$ and MRI: prospective study with histopathological correlation. J Comput Assist Tomogr 29: 64-68.

5. Haferkamp A, Bastian PJ, Jakobi H, Pritsch M, Pfitzenmaier J, et al. (2007) Renal cell carcinoma with tumor thrombus extension into the vena cava: prospective long-term followup. J Urol 177: 1703-1708.

6. Ciancio G, Vaidya A, Savoie M, Soloway M (2002) Management of renal cell carcinoma with level III thrombus in the inferior vena cava. J Urol 168: 1374-1377. 